\title{
APLASIA CUTIS CONGENITAL WITH AMNIOTIC BAND DISRUPTION COMPLEX: A RARE CASE REPORT
}

Pradipprava Paria1, Ramesh Chandra Halder², Sibarjun Ghosh ${ }^{3}$

\section{HOW TO CITE THIS ARTICLE:}

Pradipprava Paria, Ramesh Chandra Halder, Sibarjun Ghosh. "Aplasia Cutis Congenital With Amniotic Band Disruption Complex: A Rare Case Report". Journal of Evolution of Medical and Dental Sciences 2015; Vol. 4, Issue 74, September 14; Page: 12960-12962, DOI: 10.14260/jemds/2015/1869

ABSTRACT: Aplasia cutis congenita (ACC) is congenital absence of skin, most commonly affecting scalp. Etiology is multifactorial like intrauterine infection, teratogens, vascular causes, genetic syndromes etc. We here represent an infant with ACC involving extremities and associated with amniotic band disruption complex. He was treated conservatively and discharged.

KEYWORDS: Aplasia cutis congenita, Involvement of extremities, Amniotic band disruption complex.

INTRODUCTION: Aplasia cutis congenita (ACC) is a rare congenital disorder characterized by a localized absence of skin and dermal appendages. It most commonly (84\%) presents as a solitary defect of the scalp but may also involve the trunk and extremities. The lesions are non-inflammatory, well demarcated and have variable extent range from 0.5 to $10 \mathrm{~cm}$ or more. ${ }^{1,2}$ The cause is not clear but genetic factors, compromised vasculature to the skin, infection, amniotic band, teratogens, fetus papyraceous and trauma are all implicated.,3 Management is conservative and rarely surgical. Here we report a case of aplasia cutis with amniotic band disruption complex.

CASE REPORT: A 1-day old preterm (34 weeks) male neonate, born by vaginal delivery with birth weight of 1750 gram, length $48 \mathrm{~cm}$ and head circumstance $30 \mathrm{~cm}$, admitted in our nursery because of bilateral extensive areas of denuded skin in both lower limbs and left forearm. No history of medications or varicella or herpes infection was there during the antenatal period. No family history of similar condition was there. On physical examination, these lesions were gelatinous, symmetric involving anterior, lateral and medial aspects of both the leg extending up-to mid-thigh and dorsum of foot. It also involves volar aspect of left forearm. Constriction band was there around right wrist joint and below the mandible extending up-to ears, causing deformation of both the ears. No scalp lesion was there. There was no other organ involvement. Routine investigations were within normal limits. Ultrasonography of the abdomen and central nervous system revealed no abnormalities. Child managed conservatively with cotton padding and topical antibiotics and discharged. 


\section{CASE REPORT}

Fig 1: showing congenital absence of skin in leg extending up-to mid-thigh and dorsum of foot and also over volar aspect of forearm. Constriction band was there around right wrist joint and below the mandible.

Fig 2: showing amniotic band around right wrist joint.

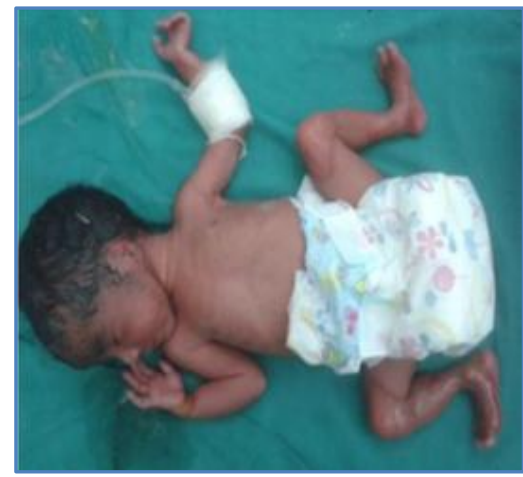

Fig. 1

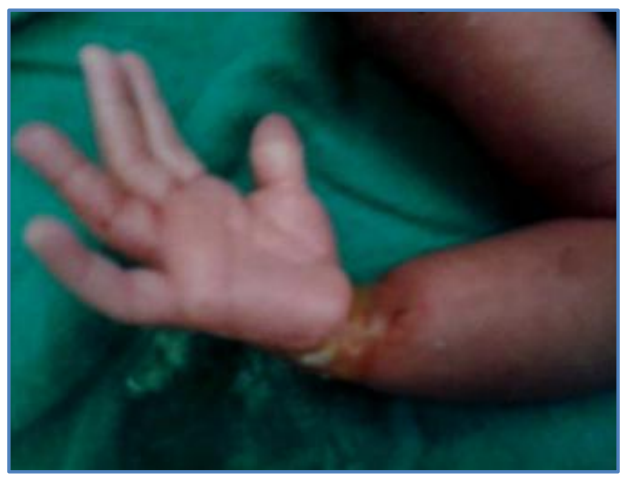

Fig. 2

DISCUSSION: Aplasia cutis congenita (ACC), congenital absence of skin, is an uncommon anomaly, presented at birth. Incidence is 1 in every 10, 000 live births with no racial or sexual predilection. ${ }^{5}$ Most published cases of ACC are sporadic; with a few reports describing a familial occurrence in the form of autosomal dominant ${ }^{6}$, as well as autosomal recessive ${ }^{7}$ pattern of inheritance. ACC may occur anywhere in the body; however, in $84 \%$ of cases, the defect is found in the scalp, ${ }^{8}$ where it is often solitary and located predominately in the midline vertex. Non-scalp lesions may involve the trunk and/or extremities and are usually bilaterally symmetric. ${ }^{9}$ At birth, the appearance of the lesion may vary from superficial erosion to a deep ulcer with the affected area covered with a thin, transparent membrane. When the lesion occurs early in pregnancy, it may heal before delivery leaving a congenital atrophic alopecic scar. The exact etiology of ACC is still unclear but intrauterine infection by varicella or herpes virus, drugs such as methimazole, misoprostol, valproate, cocaine, marijuana etc., fetus papyraceus, feto-fetal transfusion, vascular coagulation defects, amniotic membrane adherence, abnormal elastic fiber biomechanical forces and trauma are implicated.10 The main complications of larger defects include infection, bleeding and thrombosis that may be fatal.

Although ACC usually benign, they can be associated by a lot of physical anomalies and chromosomal disorders. Hence, Frieden, ${ }^{11}$ created a classification system for ACC consisting of nine groups based on the number and location of the lesions and the presence or absence of associated malformations. Our case is type 9 of Frieden classification system i.e, ACC as a part of malformation syndrome. Diagnosis of ACC is clinical with a few reports on histopathology, which reveal absence of epidermis, dermis, adnexa and sometimes subcutaneous tissue depending upon the depth of the defect. ${ }^{12}$ Regular ultrasonography during antenatal checkup sometime helps in early diagnosis of ACC. The management of non-scalp ACC is still controversial. Most lesions heal spontaneously with conservative dressing with application of the bland ointment or topical antibiotic ointment, but larger lesions may necessitate surgical interference with skin grafts or local skin flaps. ${ }^{13}$ 


\section{REFERENCES:}

1. Mark A. Crowe. Aplasia cutis congenita. Section 2-9. E-medicine.com.inc.2004

2. Suarez 0, Lopez-Gutierrez JC, Andrés A, et al. Aplasia cutis congenita: Surgical treatment and results in 36 cases. Cir Pediatr. 2007; 20(3):151-5.

3. Cambiaghi S, Schiera A, Tasin L, et al. Aplasia Cutis jongenita in surviving cotwins. Pediatr Dermatol. 2001; 18(6):511-5.

4. Fagan LL, Haris PA, Coran AG, et al. Sporadic aplasia congenita. Pediatr SurInt. 2002; 8(5-6):545-7.

5. Taifour Suliman M, Quazi A. Aplasia cutis congenita of the trunk in a Saudi newborn. Br J Plast Surg.2004; 57: 582-4.

6. Fimiani M, Seri M, Rubegni P, Cusano R, De Aloe G, Forabosco P, et al. Autosomal dominant aplasia cutis congenita: report of a large Italian family and no hint for candidate chromosomal regions. Arch Dermatol Res. 1999; 21: 637-42.

7. Lestringant G, al Towairky A. Three siblings with extensive aplasia cutis congenita of the scalp and underlying bone defect: autosomal recessive inheritance. Int J Dermatol. 1989; 28: 278-9.

8. Demmel U. Clinical aspects of congenital skin defects. I congenital skin defects on the head of the newborn. Eur J Pediatr. 1975; 121: 21-50.

9. Mannino FL, Jones KL, Benirschke K. Congenital skin defects and fetus papyraceus. J Pediatr.1977; 91: 559-64.

10. Tempark T, Shwayder TA. Aplasia cutis congenita with fetus papyraceus: Report and review of the literature. Int J Dermatol 2012; 51: 1419-26.

11. Frieden IJ. Aplasia cutis congenita: A clinical review and proposal for classifi cation. J Am Acad Dermatol 1986; 14: 646-60.

12. Moss C, Shahidulla H. Naevi and other developmental defects. In: Burns T, Breathnach S, Cox N, Griffiths C, editors. Rook's Textbook of Dermatology. 8 th ed. United Kingdom (UK): WileyBlackwell Publication; 2010. p. 18, 18.98-18.106.

13. Ahcan U, Janezic T. Management of aplasia cutis congenita in a non-scalp location. Br J Plast Surg.2002; 55: 530-2.

\section{AUTHORS:}

1. Pradipprava Paria

2. Ramesh Chandra Halder

3. Sibarjun Ghosh

\section{PARTICULARS OF CONTRIBUTORS:}

1. RMO-Cum-Clinical Tutor, Department of Paediatrics, RG Kar MC.

2. RMO-Cum-Clinical Tutor, Department of Paediatrics, RG Kar MC.

3. Professor \& HOD, Department of Paediatrics, RG Kar MC.

NAME ADDRESS EMAIL ID OF THE CORRESPONDING AUTHOR:

Pradipprava Paria,

R G Kar M C,

1, Khudiram Bose Sarani,

Kolkata-4.

E-mail: drpradip83@gmail.com

Date of Submission: 24/08/2015.

Date of Peer Review: 25/08/2015.

Date of Acceptance: 07/09/2015.

Date of Publishing: 14/09/2015. 